\title{
DESIGN AND EVALUATION OF GUARGUM - BASED TIMOLOL MALEATE OCULAR INSERT
}

\author{
Sunil Kumar*, Roshan Issarani, B. P Nagori
}

Lachoo Memorial College of Science and Technology, Pharmacy Wing, Jodhpur-342 003, Rajasthan, India

Submitted: $13-04-2015$ Revised: 17-05-2015 Accepted: 21-06-2015

*Corresponding author Sunil Kumar

Email:

Sunil.thakral@gmail.com

\begin{abstract}
The objective of this study was to prepare ocular inserts of timolol maleate using guar gum as a polymer. Timolol maleate ocular inserts were prepared by solvent casting method using guar gum in different proportions $(0.25 \% \mathrm{w} / \mathrm{v}, 0.50 \% \mathrm{w} / \mathrm{v}, 75 \%$ $\mathrm{w} / \mathrm{v}$ and $1.0 \% \mathrm{w} / \mathrm{v})$. The prepared formulations were evaluated for thickness, weight variation, percentage drug content, surface $\mathrm{pH}$, folding endurance, percentage moisture absorption and loss, percentage swelling, mechanical strength and in vitro transcorneal permeation. In-vitro transcomeal permeation study was performed on goat cornea using modified Franz diffusion cell. The inserts were found to be of uniform thickness (ranging from $41.12 \pm 0.04 \mu \mathrm{m}$ to $79.90 \pm 0.03 \mu \mathrm{m})$ and weight $(0.84 \pm 0.07 \mathrm{mg}$ to $2.11 \pm 0.09 \mathrm{mg})$. The \% drug content in the inserts was found to be varied between $98.69 \pm 0.58$ to $96.37 \pm 0.58$. The cumulative \% drug releases from the formulation ranged from $50.22 \pm 1.41$ to $97.72 \pm 0.670$ ver a period of $24 \mathrm{~h}$. In-vitro transcorneal study revealed that an increase in concentration of polymer slows down the release of timolol maleate from the formulation. Ocular inserts using guar gum as a polymer were successfully prepared and can be effectively used for sustain ocular delivery over a period of $24 \mathrm{~h}$.
\end{abstract}

Key words: Guar gum, in vitro transcomeal permeation study, ocular insert, timolol maleate, sustained release

\section{INTRODUCTION}

Glaucoma, a disease characterized by the rise in intraocular pressure (IOP), is the second largest cause of blindness worldwide and has now become not only a disease of elevated IOP but also as an optical neuropathy. (Bhagav et. al., 2011). Glaucoma is a group of diseases of the optic nerve involving loss of retinal ganglion cells and optic nerve axons in a characteristic pattern of optic neuropathy. (www.lotuseyecare.com/ 2012; Goach, 2012). It is a condition of elevated IOP associated with progressive death of retinal ganglionic cells and subsequently is untreated, results in progressive retinal damage, visual field loss and blindness. The current drug therapy of glaucoma includes topical administration of drugs such as beta blocker (timolol maleate, betaxalol), carbonic anhydrase inhibitor (acetozolamide, dorzolamide, brizolamide), prostaglandins (latanoprost, brinoprost, unoprostone) or alphaagonist (brimonidine tartrate) (Saxena, 2002).
Timolol maleate is widely used as a topically applied $\beta$-adrenergic-blocking agent in ophthalmology to lower the intraocular pressure of glaucoma patients. It is given in divided dose several times in a day in the form of eye drop. Eye drop preparations though widely used suffer from the drawback of rapid drainage of drug out of the eye or into nasolacrimal pathway due to rapid tear turnover resulting in loss or systemic absorption of the drug. While loss of drug results in compromised therapeutic efficacy, systemic absorption results in undesired side effect. It is well known that topically administered timolol may cause severe cardiovascular and respiratory side effects due to systemic absorption. It is important to minimize the systemic absorption and enhance ocular bioavailability of timolol maleate. Improvement of ocular bioavailability can permit reduction of the instillation frequency or of the dose, with a consequent decrease in undesired side effects. For this reason, various 
studies have been carried out with the aim of improving the ocular bioavailability of timolol; these included the use of a prodrug, of an ophthalmic insert or of a gel-forming solution. (Titcomb, 2008).

Ophthalmic inserts are probably a good choice for this purpose since they increase the contact time with the conjunctival tissues. They offer the following advantages: increased ocular residence time, drug release at a slow and constant rate, accurate dosing, reduction of systemic absorption, better patient compliance, possibility of targeting internal ocular tissues and increased shelf-life with respect to aqueous solutions (El-Gamal, 2008).

For ocular inserts, the following criteria are essential. Elution kinetics of the effective drug from the insert should be of zero or nearly zero order for a long time. The insert should be harmless when retained in the eye for a long time. The insert must stay easily in the eye and not give any disagreeable feeling to the patients. (Ozawa, 1983).

Guar gum is a natural water-soluble nonionic galactomannan polysaccaride, obtained from the ground endosperm of Indian cluster bean Cyamposis tetragonolobus (L.) Taub. (Family-Leguminosae). It has the ability to produce highly viscous, pseudoplastic aqueous solutions even at low concentrations due to the high molecular weight (upto $2 \mathrm{MDa}$ ) and due to the presence of extended repeating unit formed by hydrogen bonding. This feature allows guar gum to be soluble and gelling even in cold water. The therapeutic effect of guar gum is due to its ability to swell rapidly in aqueous media to form viscous dispersions or gel (Iqbal, 2010).

Alhough extensive research work has been reported on ocular inserts, it could be evidenced from the literature that guar gum is not reported as a polymer in ocular inserts. As guar gum is the main ingredient in SYSTANE eye drops, used in dry eye disease (Matheson, 2011) and guar gum with borax crosslinking is used in ophthalmic composition, therefore it can also be used as a polymer in ocular inserts. (Asgharian, 2007). Thus, the present research work was undertaken with a view to prolong the ocular residence time as well as contact between eye and release of drug by incorporation them in an inserts.

\section{MATERIALS AND METHODS}

Timolol maleate was obtained as a gift sample from Micro Labs Ltd., Bangalore, India. Guar gum was procured from Ases Chemicals, Jodhpur, India. Sodium chloride, sodium bicarbonate and calcium chloride dihydrate were purchased from S.D. Fine Chemicals, Mumbai, India. Dibutylphthalate was purchased from Loba Chemicals, Mumbai, India. All the chemicals used were of I.P. / A.R. or equivalent grade.

\section{Preparation of ocular insert}

The ocular inserts were prepared by the solvent casting method. (Rathore, 2010). Four batches (Batch A-Batch D) of timolol maleate ocular inserts were prepared using different concentrations of guar gum (Table I). Required amounts of guar gum were weighed and dissolved in distilled water by pouring guar gum gradually with vigorous stirring. The mixture was stirred for 2-4h for complete hydration of guar gum. Required amount of plasticizer (dibutylphthalate $-30 \% \mathrm{w} / \mathrm{w}$ of the polymer) was added followed by the drug and stirring was continued to form a homogenous solution. After complete mixing, the solution was kept overnight to remove any entrapped air bubbles. The solution $(10 \mathrm{~mL})$ was poured into glass moulds $\left(35 \mathrm{~cm}^{2}\right)$, which were then placed on a flat surface and were covered by an inverted funnel with cotton plug to prevent aerial contamination and to allow slow and uniform evaporation at room temperature for $48 \mathrm{~h}$. The dried films so obtained were peeled from the casting surface and cut into an appropriate size (8mm diameter) using a sterile stainless steel borer. An area of $0.50 \mathrm{~cm}^{2}$ containing $85.6 \mu \mathrm{g}$ of timolol maleate was used in all studies.

These formulations were sterilized separately by exposing to UV radiation for 90 min in a cabinet under aseptic conditions and were finally packaged in pre sterilized aluminum foil. The ocular inserts were placed in a desiccator until use (Tanwar, et al., 2007).

\section{Evaluation of the timolol maleate ocular inserts Thickness of film}

The thickness of 10 randomly selected ocular inserts of each formulation was measured using a trianocular microscope. 
Table I. Composition of polymeric matrices for the different formulation

\begin{tabular}{lcccc}
\hline & F1 & F2 & F3 & F4 \\
\hline Timolol maleate $(\mathrm{mg})$ & 60 & 60 & 60 & 60 \\
Guar gum $(\% \mathrm{w} / \mathrm{v})$ & $0.25 \%$ & $0.50 \%$ & $0.75 \%$ & $1.0 \%$ \\
Dibutyl phthalate $(\mathrm{w} / \mathrm{w}$ of polymer) & $30 \%$ & $30 \%$ & $30 \%$ & $30 \%$ \\
Purified water $(\mathrm{mL})$ & 100 & 100 & 100 & 100 \\
\hline
\end{tabular}

Table II. Evaluation of ocular inserts

\begin{tabular}{ccccc}
\hline Code & Thickness $(\boldsymbol{\mu m})$ & Weight $\mathbf{( m g )}$ & Surface $\mathbf{p H}$ & \% drug content \\
\hline Batch A & $41.12 \pm 0.04$ & $0.84 \pm 0.07$ & $6.5-7.0$ & $98.69 \pm 0.58$ \\
Batch B & $54.52 \pm 0.03$ & $1.07 \pm 0.04$ & $6.5-7.0$ & $99.66 \pm 0.88$ \\
Batch C & $69.09 \pm 0.05$ & $1.68 \pm 0.10$ & $6.5-7.0$ & $97.92 \pm 0.67$ \\
Batch D & $79.90 \pm 0.03$ & $2.11 \pm 0.09$ & $6.5-7.0$ & $96.37 \pm 0.58$ \\
\hline
\end{tabular}

The mean thickness and standard deviation were calculated and presented in table II.

\section{Weight variation}

Weight variation between the formulated films can lead to difference in drug content and in vitro behavior.

The weight variation test was carried out using an electronic balance. Ten inserts from each batch were ran'domly selected and, weighted individually. The average weight and standard deviations of weight variation were calculated. (Karthikeyan et. al. 2008; Kerur et. al. 2010).

\section{Surface pH determination}

The surface $\mathrm{pH}$ of the inserts was determined by placing two drops of double distilled water over it, allowing it to swell. After this, the swollen devices were placed on the $\mathrm{pH}$ paper to determine the surface $\mathrm{pH}$. After $1 \mathrm{~min}$ the color that developed was compared with the standard color scale (Gorle et al., 2009). The results are presented in table II.

\section{Folding endura nce value}

The folding endurance is expressed as the number of folds or number of times the inserts are folded at the same place, either to break the specimen or to develop visible cracks. This test is important to check the ability of the sample to withstand folding. This also gives an indication of brittleness. The specimen was folded in the center, between the fingers and the thumb, and then opened. This was termed as one folding. The process was repeated till the insert showed breakage or cracks in the center of the inserts. The total folding operations were named as folding endurance value. (Kerur et al., 2010; Gorle et al., 2009; Gupta et al., 2007; Mishra et al., 2008; Kumar et al., 2009)

\section{Moisture absorption}

Ocular inserts were weighed and hung in a desiccator containing $100 \mathrm{~mL}$ of saturated solution of ammonium chloride (79.5\% humidity at $20^{\circ} \mathrm{C}$ ). After 3 days, the ocular inserts were taken out and re-weighed. (BPC, 1986; Hornof, 2003). The percentage moisture absorption was calculated using the following formula:

Moisture absorption (\%) $=\frac{\mathrm{W}_{\mathrm{F}}-\mathrm{W}_{\mathrm{I}}}{\mathrm{W}_{\mathrm{I}}} \times 100$

Where $\mathrm{W}_{\mathrm{I}}$ and $\mathrm{W}_{\mathrm{F}}$ are the initial and final w eights of the ocular inserts, respectively.

\section{Moisture loss}

Ocular inserts were weighed and kept in the dessicator containing anhydrous $\mathrm{CaCl}_{2}$. After 3 days, the inserts were taken out and reweighed. ((Mishra et. al., 2008; Kumar et. al., 2009; Dandagi et. al., 2004). The \% moisture loss was calculated using the following formula:

Moisture loss (\%) $=\frac{\mathrm{W}_{\mathrm{I}}-\mathrm{W}_{\mathrm{F}}}{\mathrm{W}_{\mathrm{I}}} \times 100$

Where $\mathrm{W}_{\mathrm{I}}$ and $\mathrm{W}_{\mathrm{F}}$ are the initial and the final weights of the ocular inserts, respectively. 


\section{Swelling Study}

Swelling of the polymer depends on the concentration of the polymer, ionic strength and the presence of water. Water uptake was determined gravimetrically. The insert were placed on a filter paper, which was presoaked overnight in an agar gel plate $(2 \% \mathrm{~m} / \mathrm{v}$ agar in STF, $\mathrm{pH}$ 7.2) and weighed (presoaked filter paper + insert). The inserts were incubated at $32^{\circ} \mathrm{C}$, (the eye surface temperature). Inserts with filter paper were removed at predetermined time periods and the surface water was removed with the help of a filter paper and rew eighed using an analytical balance (Hornof et al., 2003; Thakral et al., 2011). The \% of swelling was calculated using the following formula:

$\%$ Swelling $=\frac{\mathrm{W}_{\mathrm{t}}-\mathrm{W}_{0}}{\mathrm{~W}_{0}} \times 100$

Where $W_{t}$ is the weight of swollen insert after time $\mathrm{t}$ and $\mathrm{W}_{0}$ is the initial weight of the insert.

\section{Mechanical strength}

Ocular inserts with good tensile strength and percent elongation would resist tearing due to stress generated by the blinking action of the eye. Percentage of elongation at the break and tensile strength of the film were measured using a pully-based tensile strength apparatus. The total weight necessary to break the film (weight of pan + weight on pan) was noted as the break force and the simultaneous distance travelled by the pointer on the graph paper indicated the elongation at the break. (Gorle et al., 2009; Kumar et al., 2009; Rao et al., 2010).

Tensile Strength $\left(\mathrm{g} / \mathrm{mm}^{2}\right)=$ Break Force $X \frac{1+\Delta \mathrm{L} / \mathrm{L}}{\text { a.b }}$

Where $\Delta \mathrm{L}=$ elongation at break

$\mathrm{L}=$ length of the film

$\mathrm{a}=$ width of film

$\mathrm{b}=$ thickness of film

Break force $=$ weight required to break the film

$\%$ elongation at break $=\frac{\left(l_{b}-1_{0}\right)}{l_{0}} \times 100$

$1_{0}=$ original length of film

$l_{b}=$ length of film at break when stress is applied

\section{Drug content}

Drug content was determined by assaying the inserts. The optimized ocular insert was placed into a $10 \mathrm{~mL}$ volumetric flask containing simulated tear fluid of $\mathrm{pH} 7.2$ and sonicated for $20 \mathrm{~min}$ to extract the drug from the insert. The resultant solution was filtered through a G-2 glass filter. (Kumar et al., 2009). From this, the sample was taken, diluted suitably and analyzed spectrophotometrically by measuring the absorbance at $294.50 \mathrm{~nm}$.

\section{In vitro transcorneal permeation study Corneal preparation}

The whole eye ball of the sheep was obtained from a local butcher's shop within half an hour of slaughtering of the animal, and was transported to the laboratory in cold $\left(4^{\circ} \mathrm{C}\right)$ normal saline $(0.9 \% \mathrm{w} / \mathrm{v} \mathrm{NaCl})$ immediately. The cornea was carefully excised along with 2 $4 \mathrm{~mm}$ of the surrounding scleral tissues and was washed with cold normal saline till it was free from proteins.

\section{Permeation experiment}

Fresh cornea was mounted by sandwiching the surrounding scleral tissue between the clamped donor and the receptor cells of modified version of a Franz diffusion cell in such a way that its epithelial surface (apical) faced the donor compartment and the endothelial surface faced the receptor compartment. The cell was placed on a magnetic stirrer in a holding position. The receptor compartment was filled with $11 \mathrm{~mL}$ of freshly prepared simulated tear fluid $(\mathrm{pH} 7.2)$ and stirred using Teflon-coated magnetic stir bar. The ocular insert was placed to the epithelial side of the cornea in the donor cell and stirring of the receptor fluid (jacketed with water at $32 \pm 1^{\circ} \mathrm{C}$ ) was started. At appropriate intervals, $1 \mathrm{~mL}$ samples were withdrawn from the receptor compartment and the withdrawn sample volume was replaced with an equal volume of fresh simulated tear fluid to ensure sink conditions. The withdrawn samples were filtered and, diluted suitably with STF and analyzed spectrophotometrically (Simantzu 1800) by measuring the absorbance at the $\lambda_{\max }$. of $294.50 \mathrm{~nm}$. Each experiment was continued for about $24 \mathrm{~h}$. and was performed in triplicate. 


\section{Mechanism and kinetics of drug release}

In order to understand the mechanism and kinetics of drug release, the results of the in vitro drug release study were fitted with various kinetic equations like first order $(\log \%$ unreleased vs time), Higuchi matrix (\% release vs square root of time), in order to define a model which will represent a better fit for the formulation, drug release data further analyzed by Peppas equation, $\mathrm{Mt} / \mathrm{M} \infty=\mathrm{kt}^{\mathrm{t}}$. Where $\mathrm{Mt}$ is the fraction of drug released at time $\mathrm{t}$ and $\mathrm{M} \infty$ is the amount released at time $\infty$, the $\mathrm{Mt} / \mathrm{M} \infty$ is the fraction of drug released at time $t, k$ is the kinetic constant and $\mathrm{n}$ is the diffusional exponent, a measure of the primary mechanism of drug release. $\mathrm{R}^{2}$ values were calculated for the linear curves obtained by regression analysis of the above plots.

\section{RESULTS AND DISCUSSIONS Thickness}

The prepared timolol maleate ocular inserts were flat surface, circular, $8 \mathrm{~mm}$ in diameter and thickness of Batch F1 to F4 between $41.12 \pm 0.041 \mu \mathrm{m}$ and $79.90 \pm 0.039 \mu \mathrm{m}$ (Table II). Hence, formulations were not thick enough to produce any irritation while placing and being in cul-de-sac.

This indicated that as the concentration of the polymer (guar gum) increased, there was an increase in the thickness of the ocular inserts. The inserts were found to possess uniform thickness within the batch.

\section{Weight}

The weights of the timolol maleate ocular inserts, varied with the amount of the guar gum, were found to be in the range of $0.84 \pm 0.07 \mu \mathrm{g}$ to $2.11 \pm 0.09 \mu \mathrm{g}$ (Table II). The low value of S.D. in the formulated batches indicated good distribution of the drug, polymer and plasticizer. These values revealed that the process was reproducible in its capability to give films of a uniform magnitude.

\section{Surface pH}

The surface $\mathrm{pH}$ of the prepared inserts was within the range of 6.5-7.0 (Table II). This indicates that the prepared inserts would not alter the $\mathrm{pH}$ of the tear fluid in the eye and they are not expected to cause irritation to the eye.

\section{Folding endura nce value}

The films were folded manually and the value recorded was more than 200 for all batches except F4, which was considered good, and revealed good film properties. The Batch B showed the maximum folding endurance. This test is important to check the ability of the sample to withstand folding. This also gives an indication of brittleness.

\section{Moisture absorption}

The moisture absorption of the prepared formulations was found to be in the range of $10.98 \pm 0.85 \%$ to $12.79 \pm 0.607 \%$. The moisture absorption study revealed that the increase in hydrophilic polymer (guar gum) concentration increased the moisture absorption. However, there was less or no change in the integrity of the film at that condition, which was observed by its physical appearance.

\section{Moisture loss}

The moisture loss of the prepared formulations was found to be in the range of $4.18 \pm 0.43 \%$ to $5.99 \pm 0.45 \%$. The results revealed that as the concentration of guar gum increases, the tendency of the inserts to lose moisture also increases. Moisture loss is carried out to check integrity of the film at dry condition.

\section{Swelling study}

The swelling index was found minimum in formulation F1 $(30.53 \pm 0.329)$ and found to be maximum in formulation F4 (35.58 \pm 0.216$)$. The results revealed that as the concentration of the guar gum was increased, the swelling index also increased.

\section{Mechanical strength}

Tensile strength

Ocular inserts with good tensile strength and percent elongation would resist tearing due to stress generated by blinking action of eye. Tensile strength measures the ability of the film to withstand rupture. The tensile strength of the timolol maleate ocular inserts increased as the total amount of polymer was increased (Table III).

Percentage elongation at break

Batch A showed the minimum \% elongation at break while Batch $\mathrm{D}$ showed the maximum \% elongation at break (Table III). 
Table III. Evaluation of ocular inserts

\begin{tabular}{ccccccc}
\hline Code & $\begin{array}{c}\text { Moisture } \\
\text { absorption (\%) }\end{array}$ & $\begin{array}{c}\text { Moisture } \\
\text { loss (\%) }\end{array}$ & $\begin{array}{c}\text { Folding } \\
\text { endurance } \\
\text { value }\end{array}$ & $\begin{array}{c}\text { Swelling } \\
\text { index (\%) }\end{array}$ & $\begin{array}{c}\text { Elongation at } \\
\text { break }\end{array}$ & $\begin{array}{c}\text { Tensile } \\
\text { strength }\end{array}$ \\
\hline Batch A & $10.98 \pm 0.85$ & $4.18 \pm 0.43$ & $225 \pm 5$ & $30.53 \pm 0.77$ & $5.83 \pm 0.14$ & $0.41 \pm 0.01$ \\
Batch B & $12.79 \pm 0.60$ & $4.60 \pm 0.84$ & $238 \pm 7$ & $32.98 \pm 0.15$ & $11.67 \pm 0.14$ & $0.58 \pm 0.02$ \\
Batch C & $11.89 \pm 0.62$ & $5.39 \pm 0.44$ & $231 \pm 3$ & $34.25 \pm 0.68$ & $17.50 \pm 0.25$ & $1.12 \pm 0.02$ \\
Batch D & $13.40 \pm 0.59$ & $5.99 \pm 0.45$ & $199 \pm 4$ & $35.58 \pm 0.92$ & $17.50 \pm 0.25$ & $1.11 \pm 0.09$ \\
\hline
\end{tabular}

Table IV. In vitro transcorneal permeation study

Time

(h)

0

1

2

3

4

6

12

24
Batch A

$0.00 \pm 0.00$

$11.49 \pm 0.63$

$18.67 \pm 0.89$

$31.00 \pm 0.30$

$45.11 \pm 1.29$

$63.65 \pm 0.66$

$82.14 \pm 0.56$

$97.72 \pm 0.67$
Cumulative $\%$ drug release

$\begin{array}{ccc}\text { Batch B } & \text { Batch C } & \text { Batch D } \\ 0.00 \pm 0.00 & 0.00 \pm 0.00 & 0.00 \pm 0.00 \\ 8.73 \pm 0.36 & 8.30 \pm 0.64 & 6.81 \pm 0.37 \\ 14.51 \pm 0.64 & 12.06 \pm 1.11 & 9.73 \pm 0.42 \\ 22.51 \pm 0.85 & 18.34 \pm 1.64 & 12.73 \pm 0.53 \\ 32.84 \pm 1.23 & 26.05 \pm 1.35 & 17.03 \pm 1.19 \\ 44.95 \pm 1.480 & 34.21 \pm 1.31 & 23.98 \pm 1.73 \\ 58.48 \pm 2.38 & 49.27 \pm 2.53 & 36.28 \pm 1.66 \\ 78.04 \pm 2.54 & 65.39 \pm 3.05 & 50.22 \pm 1.41\end{array}$

Table V. Data for determination of kinetics of drug release of timolol maleate ocular inserts

\begin{tabular}{cccccc}
\hline \multirow{2}{*}{ Model fitting } & & \multicolumn{3}{c}{ Formulation } \\
& & F1 & F2 & F3 & F4 \\
\hline Zero order & $\mathbf{r}$ & 0.8139 & 0.8320 & 0.8974 & 0.9975 \\
1st order & $\mathbf{r}$ & 0.9965 & 0.9761 & 0.969 & 0.999 \\
Higuchi & $\mathbf{r}$ & 0.9284 & 0.9705 & 0.9799 & 0.9314 \\
& $\mathbf{r}$ & 0.6885 & 0.9537 & 0.9722 & 0.9897 \\
Peppas & $\mathbf{K}$ & 1.0944 & 1.0011 & 0.9387 & 0.8204 \\
& $\mathbf{n}$ & 0.6885 & 0.7093 & 0.6823 & 0.6616 \\
Best fit model & & First & First & Higuchi & First \\
\hline
\end{tabular}

\section{Drug content}

The drug content was consistent in all batches and varied from $96.37 \pm 0.58 \%$ to $99.66 \pm 0.88 \%$. The drug content uniformity values owed the fact that the process used was capable of giving films with uniform drug content, with unsubstantial differences in the targeted drug loading.

\section{In vitro tra nscorneal permeation study}

The cumulative percent of timolol maleate released from the ocular inserts as a function of time is shown in Figure 1. The overall cumulative percentage drug release for formulation F1-F4 was found to be 97.72 , 78.04, 65.39 and 50.22, respectively, at the end of $24 \mathrm{~h}$, as shown in table IV. The process of drug release from a guar gum drug matrix involves water penetration into the dry matrix, hydration and swelling of the polymer, and diffusion of the dissolved drug in the matrix.

\section{Drug release kinetics}

The data obtained from the in vitro transcorneal permeation studies of all four batches were subjected to kinetic treatment in order to determine the order of release. The results are shown in table $\mathrm{V}$. The release constants were calculated from the slope of the respective plots. It indicated that the release of drug from the film might have followed first order kinetics. The value for $\mathrm{n}$ was found more than 0.45 indicating that the release mechanism followed anomalous (non-fickian) transport. 


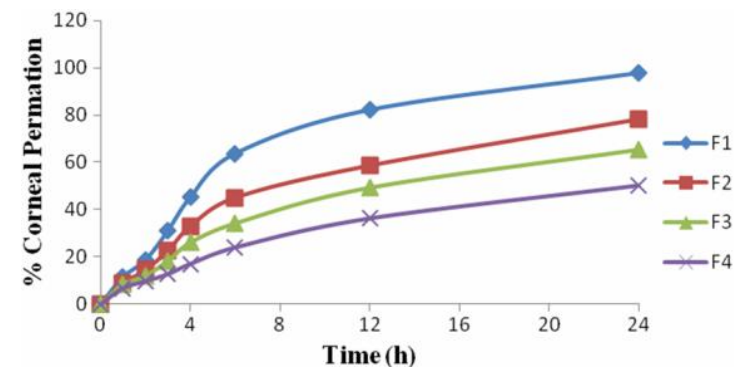

Figure 1. Cumulative $\%$ drug release versus time

\section{CONCLUSION}

The present investigation was undertaken with the objective of preparing a sustained release ocular delivery system of timolol maleate using guar gum as the polymer. The guar gum ocular inserts of timolol maleate showed appreciable film-forming properties. The study indicates potential usefulness of the guar gumbased ocular insert to provide an effective and time constant controlled delivery of timolol maleate. It was found to be effective in prolonging drug release. After hydration of the gum, the drug release from the matrix depends on the releasing are produced. Swelling of the gum attains a steady state after initial hydration, and the drug is released in a sustained fashion over a lo9ng period of time.

\section{ACKNOWLEDGEMENTS}

Timolol maleate was obtained as a gift sample from Micro Labs Ltd., Bangalore, India.

\section{REFE RE NCES}

Asgharian B. 2007. Ophthalmic composition containing galactomannan polymers and borate. United States Patent. US 2007/0098677 A1 dated May 3,

Bhagav P., Trivedi V., Shah D. 2011. Sustained release ocular inserts of brimonidine tartrate for better treatment in openangle glaucoma, Drug Deliv. And Transl. Res. 1: 161-174

Constant Humidity solution, British Pharmaceutical Codex. Great Britain: Pharmaceutical Society of Great Britain; 1986:696.

Dandagi PM., Manvi FV., Patil MB., Mastiholimath VS., Rathod R. 2004; Development and evaluation of ocular films of cromolyn sodium. Indian J Pharm Sci. 66:309-12.

El-Gamal SS., Naggar VF., Allam AN. 2008; Formulation and evaluation of acyclovir ophthalmic inserts. Asian J Pharm Sci 3:58-67.

Goach N., Molokhia SA., Condie R., 2012. "Ocular drug delivery for glaucoma management," Pharmaceutics, Vol. 4: 197211.

Gorle AP., Gattani SG. 2009, Design and evaluation of polymeric ocular drug delivery system. Chem. Pharm. Bull:;57:914-9.

Gupta A., Sharma SK., Ahuja M. 2007. In vitro and in vivo evaluation ofg based ocular inserts of phenylephrine. Acta Pharm Sci; 49:55-63.

Hornof M., Weyenberg W., Ludwig A., Schnurch AB. 2003. Mucoadhesive ocular inert based on thiolated poly(acrylic acid): develoment and in vivo evaluation in humans. J Control Release 89:419-28.

http://www.lotuseyecare.com/our-services/ glaucoma-management.html accessed on dated 20-042012

Iqbal DN., Hussain EA. 2010. Physiochemical and pharmaceutical properties of guar gum derivatives. Report and Opinion 2 (10) 77-83

Karthikeyan D., Bhow mick M., Pandey VP., Sengottuvelu S., Sonkar S., Gupta N., Mohod V., Shivakumar T. 2008; Design and evaluation of ofloxacin extended release ocular inserts for once a day therapy. Res J Pharm Tech 1:460-8.

Kerur S., Dandagi P., Deshpande P. 2010; Controlled release polymeric ocular inserts for delivery of acyclovir. Turk $J$ Pharm Sci 7:75-90.

Kumar A., Mittal A., Kumar S., Singh A., Gupta A. 2009; Effect of gelrite concentration on the release through ocular inserts of ciprofloxacin hydrochloride. J Pharm Res. 2:487-90.

Matheson A. 2011., Your patient has dry eyewhat treatments are available. Education. Available from: http://www.ocularsolutions.com[Last accessed on dated June12]. 
Mishra DN., Gilhotra RM. 2008. Design and characterization of bioadhesive in-situ gelling ocular inserts of gatifloxacin sesquihydrate. DARU 2008;16:1-8.

Ozawa H., Hosaka S., Kunitoma T., Tanzawa H. 1983. Ocular inserts for controlled release of antibiotics. Biomaterials 4:170-4.

Rao MP., Nappinnai M., Raju S., Rao VU., Reddy BV. 2010; Fluconazole ocular inserts: Formulation and in vitro evaluation. J. Pharm Sci Res. 2:344-50.

Rathore KS., Nema RK., Sisodia SS. 2010; Preparation and characterization of timolol maleate ocular films. Int. J. Pharm. Tech. Res. 2:1995-2000.
Saxena R., Prakasj J., Mathur P. Gupta SK. 2002. "Pharmacotherapy of glaucoma," Indian J. Pharmaceology, Vol. 34: 71-85.

Tanwar YS., Patel D. 2007; Sisodia SS. In vitro and in vivo evaluation of ocular inserts of ofloxacin. DARU. 15:139-45.

Thakral S., Ahuja M. 2011; Effect of formulation factors on in vitro corneal permeation of fluconazole through excised sheep cornea. Afr. J. Pharm. Sci. Pharm. 2:91-103.

Titcomb L., 2008, "An update on glaucoma treatment," The Pharmaceutical Journal, Vol. 280: 219-222. 